\title{
Mother Tongue versus English as a Second Language in Mathematical Word Problems: Implications to Language Policy Development in the Philippines
}

\author{
Judy Cañero Bautista \\ Philippine Normal University, Manila \\ bautista.jc@pnu.edu.ph \\ Ilynne San Jose Samonte \\ Philippine Normal University, Manila \\ ilynne.samonte@deped.gov.ph \\ Cecille Marie Titar Improgo \\ Philippine Normal University, Manila \\ cecilletitarimprogo@gmail.com \\ Merry Ruth Morauda Gutierrez \\ Philippine Normal University, Manila \\ gutierrez.mrm@pnu.edu.ph
}

DOI: http://doi.org/10.36892/ijlls.v2i2.283

\begin{tabular}{|c|c|}
\hline $\begin{array}{l}\text { Received: } \\
\text { 30/04/2020 }\end{array}$ & $\begin{array}{l}\text { Abstract } \\
\text { This study investigated the performance of } 150 \text { Tagalog and 131 Sinugbuanong }\end{array}$ \\
\hline $\begin{array}{l}\text { Accepted: } \\
23 / 05 / 2020\end{array}$ & $\begin{array}{l}\text { Bisaya grade three pupils with regard to solving mathematical word problems } \\
\text { written in their mother-tongue (L1) and in English as their second language } \\
\text { (L2). The respondents were subjected to a validated teacher-made parallel tests } \\
\text { based on the competencies stipulated in the first and second quarter }\end{array}$ \\
\hline $\begin{array}{l}\text { Keywords: } \\
\text { Mother tongue; English } \\
\text { as a second language; } \\
\text { Mathematical word } \\
\text { problems; } \\
\text { Language policy } \\
\text { development; } \\
\text { Translanguaging }\end{array}$ & $\begin{array}{l}\text { mathematics curriculum guide of the Philippines. Results of which were } \\
\text { compared and analyzed using two-tailed t-test. Findings show that the Tagalog } \\
\text { pupils performed better in their mother-tongue over English as their second } \\
\text { language. On the other hand, Sinugbuanong Bisaya pupils performed better in } \\
\text { English as their second language over their mother-tongue. While results } \\
\text { appear contradictory, contextual discussions offer valuable insights into the } \\
\text { situation, allowing avenues for more exploration and investigations. As } \\
\text { implication to language policy development, this study offers the use of } \\
\text { translanguaging in content area instruction and assessment, specifically in the } \\
\text { teaching and learning of mathematical problem solving. }\end{array}$ \\
\hline
\end{tabular}

1. INTRODUCTION

In recent years, the Philippines have institutionalized the mother tongue-based multilingual education (MTBMLE) through relevant policies which required the use of the pupils' mother tongue, first language, or L1 as medium of instruction and assessment in the content areas starting from kindergarten through the third grade. One rationale for the Philippines' adoption of mother tongue as medium of instruction in the early years of formal schooling is to link what the pupils 
have initially acquired and learned from their homes or immediate environments to the academic expectations, nature, or demands of the school and the curriculum.

The advocates of this curricular language policy forward that it provides for, among other things, cognitive development and higher order thinking skills of learners. Furthermore, the policy is believed to ascertain learners' strong foundations in cognitive skills development and in acquisition of academic content due to the minimal language barrier. Additionally, terms, instruction, and assessment familiar to the learners are expected to be used even at the very beginning of the school year, making academic contents more comprehensible as input to the learners.

\section{LITERATURE REVIEW}

Several issues have been observed in more recent years when the policy has been in full implementation. Williams, Metila, Pradilla, and Digo's (2014) study, for example, have noted that there were challenges in the translation of science and mathematical terms into the mother tongue of the pupils, not to mention the lack of translation equivalents of some science and mathematical terms. Conversely, they have also noted that pupils are used to counting in English even before kindergarten. This implies that in reality, there are practical challenges in the implementation of the mother tongue-based multilingual education.

It can be inferred that the original intention of the language policy is to use mother tongue in the delivery of instruction and in the administration of learning assessment. Nevertheless, it was practical for both the teachers and the learners to revert back to English as a second language when they were not able to access meaning due to the difficulty of translating the science and mathematical lexicon or simply because of the lack of mother tongue terms that are equivalent to the English terms used in science and mathematics. In addition, it can also be noted that current generation of primary school learners have already acquired science and math terms using English as a second language even before they begin kindergarten because they are already exposed to different media using several official languages.

\section{On Translanguaging and Content Area Instruction}

It has become common scenario in the Philippines' MTBMLE classrooms that teachers and learners use both mother tongue and English terms or words in content subjects or learning areas. In point of fact, the study of Williams et. al (2014) also forwards that the teaching strategies used by the primary school teachers include students' double exposure through their mother tongue and English as a second language, especially for number terms. This practice does not appear to be a case in isolation. Veritably, this is the context by which Garcia (2009) forwards translanguaging as happening in classrooms. He defines translanguaging as "the act performed by bilinguals of accessing different linguistic features or various modes of what are described as autonomous languages, in order to maximize communicative potential" (p. 140).

Translanguaging, according to Baker (2001), may offer education the following: promote a deeper and fuller understanding of the subject matter; help the development of the weaker language; facilitate home-school links and cooperation; and help the integration of fluent speakers with early learners. In addition, Creese and Blackledge (2010) found out in a study that learners understand better when a text is presented in languages that are familiar to them, even when one is a second language, and that the mixture and utility of "both languages keep the task moving forward" (p. 110). 
The earlier statement provides a premise that language matters in the performance of learners in a content area, like mathematics. It is deemed that solving word problems is actually a combination of skills in processing or comprehending written information and in mathematics. As Bautista, Mitchelmore, and Mulligan (2009) claim, learners have difficulties solving word problems when they have not reached the needed level of proficiency in the language used. The interplay between a language that is comprehensible to pupils and the skills in word problem solving is manifested in the pupils' comprehension of word problems in mathematics. The notion of math and comprehension being shared in math word problems is shared by researchers who have included these variables in their studies: Yonson (2017); Aliñab, Aguja, and Prudente (2018); Boonen, de Koning, Jolles, and van der Schoot (2016); Daroczy, Wolska, Meurers, and Neurk (2015); and Bautista, Mitchelmore, and Mulligan (2009).

Whitin and Whitin (2000), as cited in Edwards, Maloy, and Anderson (2009), contend that mathematics is a language in itself. For these authors, pupils in elementary math classes are actually confronted with different, but somehow related, languages of numbers and words, which are conveniently both found in math word problems.

Rasmussen and King (2000) and Timmermans, Van Lieshout, and Verhoeven (2007) defined mathematical word problems as exercises that have relevant information written as text, which led other scholars (Lewis \& Mayer, 1987; van der Schoot, Bakker Arkema, Horsley, and Van Lieshout, 2009; Jitendra \& Star, 2012) to say that the students' understanding or comprehension of the text forms part of effectively solving word problems, the other being their knowledge on mathematical operations.

This simply points out the idea that comprehension is a significant factor to effective mathematical performance. It is in this context that Boonen, van der Schoot, Wesel, De Vries, and Jolles (2013) concluded that word problem solving in mathematics is dependent on comprehension. Word problem solving skills, therefore, would be a difficulty for those who have trouble in comprehension. Pape (2003) further supports this argument forwarding that an important individual skill in word problem solving is the student's reading comprehension abilities.

In a study among 225 fourth grade children aged 9-10, Vilenius-Tuohimaa, Aunola, and Nurmi (2008) revealed that that the pupils' performance on mathematics word problem solving was strongly related to performance in reading comprehension. Even after controlling for the level of technical reading involved, performance in maths word problems was still related to reading comprehension. The authors pointed out that both word problem solving and reading comprehension need reasoning abilities.

\section{Mother Tongue Research in the Philippines}

If one is to comprehensively weave all the arguments provided in the various literature cited earlier, one can state that the use of mother tongue as medium of instruction in content areas like mathematics will increase the likelihood that learners comprehend better the word problems they are asked to solve. This, in turn, increases the likelihood that they perform better with mathematical word problem solving activities. Aliñab, Aguja, and Prudente (2018), for example, support this claim when they said that pupils tend to perform better in mathematics when the medium of teaching and learning is the pupils' first language. It is important to consider, however, that more familiar English terms in mathematics may also appear beneficial for the learners (Williams et al., 2014). This makes apparent that when mathematics terms have been part of the pupils' sight vocabularies, they benefit with English as their second language as well. 
It is, therefore, imperative to administer additional investigation using variables such as: 1) mother tongues from different geographical areas in the Philippines; 2) English as a second language; and 3) content area like mathematics in order to shed some light into the issues of and between MTBMLE identified by Cruz (2015); Yonson (2017); Williams et al. (2014) and content area instruction and assessment in the Philippines (Williams et al., 2014; Aliñab, Aguja, and Prudente, 2018).

\section{Research Problems}

In order to contribute potential information on the current literature as regards the use of mother tongue as a more comprehensible language for the learners' acquisition of mathematical skills in problem solving, the researchers sought to compare the pupils' performance in a parallel mathematical word problem solving test which are written in both English and in their respective mother tongues, i.e. Tagalog for Bataan learners from the northern island of the Philippines and Sinugbuanong Bisaya for Malaybalay pupils from the southern island of the country.

Specifically, this investigation sought to answer the following questions:

1. What is the performance of the Grade 3 pupils in solving the mathematical word problems written in English?

2. What is the performance of the Grade 3 pupils in solving the word problems written in their respective mother tongues (Tagalog or Sinugbuanong Bisaya)?

3. Is there a significant difference between the pupils' performance in the word problem solving when presented in English and when presented in their mother tongue?

\section{MATERIALS AND METHODS}

This study utilized a quantitative methodology, specifically the descriptive research design which compared the Grade 3 pupils' performance in word problem solving tests written in English versus written in their mother tongue. The first test was presented in English while the second test was presented in the learners' mother tongue. In the case of learners from Bataan, the second test was written in Tagalog, while for the pupils in Malaybalay, the second test was written in Sinugbuanong Bisaya.

A total of 150 Tagalog and 131 Sinugbuanong Bisaya pupils composed the number of respondents in the study. The researchers utilized purposive cluster sampling where pupils who belong to the first or prime sections, typically homogenous sections, from four central schools in the Division of Bataan, and pupils who belong to the first or prime sections from four central schools in the Division of Malaybalay were selected. Such purposive sampling is done due to the grade three pupils' full three years exposure to the implementation practices within the current MTBMLE policy in the Philippines. These pupils have undergone and have passed a screening test conducted before their enrolment, which determined their eligibility to be grouped to the prime section. They, therefore, belong roughly to the upper five percent of the Grade 3 cohort of learners. For ethical purposes, the consent of both the grade three pupils' teachers and parents were secured and none of the respondents in this study was personally identified. Therefore, all of the data for personal identification were kept in utmost confidentiality and treated only for the purpose of the current study.

A teacher-made parallel multiple-choice test developed from a table of specifications covering the lessons and competencies of Grade 3 pupils for the first and second quarter of the school year was prepared by third grade teachers who were not teaching the respondents involved 
in the study. This test was written in English and was later translated to Tagalog and Sinugbuanong Bisaya. The numerical values in the word problems written in English, however, were altered when translated to the mother tongue. This was to prevent the threat to validity which is the learners' ability to memorize the English version of the test and their use of the same calculations for the translated version if the tests were given the same figures and were not altered. Subsequently, the test was validated for content, language, and meaning by the divisions' MTBMLE Coordinator and the third grade mathematics and English teachers. There was unanimous agreement between and among the validators of the test. The validation includes a consensus that the translations of the English version were captured in the respective mother tongues of the learners from Bataan and Malaybalay.

After the administration of the test, the items were checked or marked and the mean and standard deviation were computed. The two tailed t-test was used to compare the pupils' performance in the test written in English and the test written in their respective mother tongues. Furthermore, in order to clarify essential points relative to the results of the tests, random informal retrospective interviews were made. The responses were collected randomly from the students and their third grade teachers.

Despite the absence of qualitative documentation and analysis on the actual problem solving processes or strategies that the pupils deliberately used, this study rests on the assumption that their performance, which is globally measured by their scores in the teacher-made multiplechoice tests, reflects their understanding or comprehension of the mathematical word problems since there are extensive studies that correlate reading comprehension and word problem solving performance (Harlaar, Kovas, Dale, Petrill, \& Plomin, 2012; Fuchs, Gilbert, Fuchs, Seethaler, \& Martin, 2018). In point of fact, Fuchs, et al. (2018) conclude that text comprehension and oral language are strong predictors of word problem solving. It may, therefore, be safe to assume that the higher scores the pupils have on the word problem solving tests, the more likely that they have understood the word problems. However, this assumption does not undermine the potential benefit of an available analyzed qualitative data with regard to the actual solving processes and strategies that the pupils deliberately used in order to inform readers of this study about the comprehension the pupils had about the mathematical word problems.

\section{RESULTS AND DISCUSSION}

Table 1 shows the performance of the Grade 3 pupils in their word problem solving with regard to the test presented in English. Among the four schools that participated in the study, Division A (Tagalog - Bataan) shows two schools whose pupils performed above the passing mean percentage score (MPS), which is $75 \%$ based on the Philippine grading system. Two schools performed above the passing MPS, while the other two did not reach the passing mark. It can be noted that the last two schools' performance is below the passing MPS. As for the performance of pupils from Division B (Sinugbuanong Bisaya - Malaybalay), all participants' MPS were below the $75 \%$ passing standard.

Additionally, Table 1 manifests the performance of the participants in their word problem solving with regard to the test presented in their respective mother tongues. For Division A pupils, the same pattern can be seen based on their performance in the English version of the test. Two schools obtained a mean percentage score above the passing rate, while the other two did not make it to the passing mean percentage score. As for Division B, their performance in the mother tongue version of the test is also reflective of their performance in the English version of the test. All schools were not able to reach the MPS of $75 \%$. 
Table 1. Grade 3 Pupils' Performance in Word Problem Solving in English and Mother Tongue

\begin{tabular}{lccccc}
\hline Division & $\begin{array}{l}\text { Number of } \\
\text { Pupils (N) }\end{array}$ & \multicolumn{2}{c}{ Mean $(\overline{\boldsymbol{x}})$} & \multicolumn{2}{c}{ Mean Percentage Score (MPS) } \\
\hline $\begin{array}{l}\text { Bataan } \\
\text { (Division A) }\end{array}$ & $\mathbf{1 5 0}$ & English & Tagalog & English & Tagalog \\
\hline School A & 37 & 8.00 & 7.74 & 80.00 & 77.40 \\
\hline School B & 38 & 8.10 & 8.24 & 81.38 & 82.75 \\
\hline School C & 40 & 3.65 & 6.68 & 37.77 & 67.46 \\
\hline School D & 35 & 5.17 & 6.77 & 51.71 & 67.71 \\
\hline $\begin{array}{l}\text { Malaybalay } \\
\text { (Division B) }\end{array}$ & $\mathbf{1 3 1}$ & English & $\begin{array}{c}\text { Sinugbuanong } \\
\text { Bisaya }\end{array}$ & English & $\begin{array}{c}\text { Sinugbuanong } \\
\text { School A }\end{array}$ \\
\hline School B & 34 & 3.71 & 3.08 & 37.10 & 30.80 \\
\hline School C & 29 & 3.45 & 3.83 & 34.52 & 38.39 \\
\hline School D & 36 & 3.78 & 3.27 & 37.78 & 32.78 \\
\hline
\end{tabular}

Generally, based on a $75 \%$ mean percentage score as passing rate, majority of the school sampled collectively from Division A and Division B demonstrate a dismal performance for both English and mother tongue versions of the mathematical word problems. It is important to note, however, that Division A performed better with regard to the mathematical word problem solving test written in their mother tongue. Conversely, as for Division B, the pupils appear to perform better in the English version of the mathematical word problems.

Table 2 presents the performance of the pupils in Division A (Bataan) as regards solving mathematical word problems presented in English and in their mother tongue, i.e. Tagalog. To compare whether there is a significant difference in the Grade 3 pupils' word problem solving performance presented in English and in their mother tongue, the p-value for paired sample means was computed.

Table 2. Division A's Mathematical Word Problem Solving Performance in English and Tagalog

\begin{tabular}{|c|c|c|c|c|c|}
\hline $\begin{array}{l}\text { Language Used in } \\
\text { Math Test }\end{array}$ & $\bar{x}$ & SD & t-value & p-value & Interpretation \\
\hline English & 6.205 & 3.720 & \multirow[t]{2}{*}{1.976013178} & \multirow[t]{2}{*}{0.00000} & \multirow[t]{2}{*}{ Significant } \\
\hline Tagalog & 7.358 & 0.4392 & & & \\
\hline
\end{tabular}

Data in Table 2 indicate that at $\alpha=0.05$, with the critical p-value of 0.0000 , the pupils' performance in the mathematical word problems are significantly better when mother tongue is used rather than English as a second language. This implies that there is an undeniable potential in the use of mother tongue with regard to instruction and assessment of mathematical learning. In addition, this provides evidence that when language is more comprehensible to pupils, they understand better the content of what they are learning (Bautista, Mitchelmore, and Mulligan, 2009). 
Table 3 manifests the performance of the pupils in Division B (Malaybalay) as regards solving mathematical word problems presented in English and in their mother tongue, i.e. Sinugbuanong Bisaya. Same statistical measure used in Table 2 was used to provide the meaningful data subsequently presented herein.

Table 3. Division B's Mathematical Word Problem Solving Performance in English and Sinugbuanong Bisaya

\begin{tabular}{lrr|c|c|c}
\hline $\begin{array}{l}\text { Language Used in Math } \\
\text { Test }\end{array}$ & $\bar{x}$ & \multicolumn{2}{c}{ SD } & t-value & \multicolumn{2}{c}{ p-value } & \multicolumn{1}{c}{ Interpretation } \\
\hline English & 3.695 & 1.835 & 2.29 & 0.024 & Significant \\
\cline { 1 - 3 } Sinugbuanong Bisaya & 3.397 & 1.999 & & & \\
\hline $\mathrm{N}=131$ & $\alpha=0.05$ & $* 95$ & & &
\end{tabular}

The data in Table 3 indicate that at $\alpha=0.05$, with the critical p-value of 0.024 , the mathematical word problem solving performance of the pupils is better when English as second language is used rather than the mother tongue. This appears to contradict the earlier argument that mother tongue better facilitates the comprehension of the content. However, if one is to analyze the data in Table 1 in relation to the performance of Division B's pupils, their performance for both English and mother tongue versions of the mathematical word problems was dismal. Therefore, even when English as a second language better facilitates their performance in solving mathematical word problems, English alone does not guarantee favorable performance in such tasks.

One potential explanation to the seemingly incongruent or conflicting results is the status of the mother tongue as a lingua franca. In the case of Malaybalay, Sinugbuanong Bisaya may serve as the lingua franca in that region but the linguistic profiles of the pupils could suggest that the inhabitants of Malaybalay may probably be more inclined to prefer the use of their L2 and that they may be more competent in the languages used for wider communication, which, in the Philippines' case, are English and Filipino.

Williams, et. al (2014) offer support to this claim when they forwarded that the reason for the preference in using English in certain circumstances include the following: 1) mother tongue lexicon for numbers and mathematical terms appear to be longer; 2) there is difficulty in understanding highly technical or academic terms in the mother tongue; and 3) academic competitions usually utilize English as language for general communication. Additionally, they have also found out that for some people, the use of mother tongue in instruction, especially in mathematics and science, is perceived to be beneficial only to low-achieving pupils. This implies that there is still a negative connotation in the use of mother tongue in academic discourse. It is important to note, however, that even when these perceptions are in place, their respondents still perceived mother tongue to be effective for faster learning and for less reteaching.

In the context of Bataan where the performance of the pupils clearly indicate that using Tagalog over English as L2 was indeed more beneficial to the performance of students working in mathematical word problem tasks, it is important to note that even when this result contradicts the case of Malaybalay where English appears to be more beneficial, the cases of Tagalog and Sinugbuanong Bisaya manifested in this study cannot be totally compared and contrasted without considering its contextual circumstances.

It is an undeniable fact that Tagalog comprises majority of the lexicon of the Filipino language which is one of the lingua franca and one of the official languages of the Philippines. 
Tagalog, even when it is the lingua franca and potentially the mother tongue of a select region in the Philippines, it appears to almost always possess the status of a national language. Therefore, it gives due advantage to Bataan pupils because their mother tongue is more widely and extensively used in all aspects of daily living unlike in the case of Sinugbuanong Bisaya which remains a regional lingua franca.

Relative to the random informal retrospective interviews made with pupils and their third grade teachers, the pupils have varied responses as to how they found the test in English and in their respective mother tongues. Some claimed to have found the test in English easier than the mother tongue, and others the other way around. This difference may be attributed to translanguaging that happens in class. Pupils have mentioned that their teachers often made the lessons easier when they introduced mathematics lessons using the mother tongue. They even mentioned that when the teachers explained, they made use of the common words and language that they normally use in daily conversations, the one that the pupils are very much familiar within their homes and in their immediate environments. Conversely, some pupils and teachers claimed to have used English in cases where there is no better option but to use the more familiar English lexica or because there is a lack of counterparts in the mother tongue in relation to technical or academic terms in mathematics.

For these reasons, the responses to the random informal retrospective interviews affirm Baker's (2001) claim that translanguaging promotes a deeper and fuller understanding of the subject matter. Based on the approximations of this study, it may be safe to forward that the combination of mother tongue and English as a second language is beneficial to content area instruction and assessment, especially in developing mathematical word problem solving. It would, therefore, be counterproductive to dismiss the potential of multiple languages in clarifying concepts in the teaching of mathematical problem solving. This study affirms Creese and Blackledge's (2010) statement that learners understand better when a text is presented in languages that are familiar to them, even when one is a second language, and that the mixture and utility of "both languages keep the task moving forward" (p. 110).

\section{CONCLUSION}

The performance of pupils in solving mathematical word problems presented in both their mother tongue and English as their second language differs as evidenced by the inverse or contrasting results found in two locales involved in the study. On one hand, the use of mother tongue in mathematical word problems appears to be beneficial to young learners of mathematics especially with regard to the development of their problem solving abilities. On the other hand, the use of English as second language potentially eases the burden of both the teachers and learners in their search for mother tongue counterparts or equivalents of technical or academic terminologies which are, in fact, more readily accessible through English as a second language being the language used for wider communication.

\section{Implications to Language Policy Development}

It is imperative, therefore, to consider all linguistic resources that the learners and teachers cognitively share in order to maximize the instructional and assessment episodes in the classroom. Rather than treating one language as superior to the other, language policies relevant to the school curricula should be designed to make all linguistic resources as constituents to learning academic content. Language policies should encourage translanguaging as a potent practice in the delivery and transaction of comprehensible academic content and discourse between and among teachers 
and learners. English as a second language should not be seen as the only linguistic resource for speakers of other languages especially when the community comes from a dense multilingual and multicultural backgrounds (Owojecho, 2020) but it should be seen as an additional linguistic resource for multilingual individuals.

The status of a language on the basis of being an L1 or an L2 does not seem to merit much when all the participants, i.e. teachers, learners, and texts, of the teaching and learning process interact and transact information through comprehensible languages.

\section{Recommendations and Future Directions}

This current investigation was limited to the study of two mother tongues spoken from two geographical regions of the Philippines. Researchers may want to expand the coverage of the study in order to include the more-than-a-hundred mother tongues or first languages spoken by people in the Philippines. Some researchers may also want to do a replication of this study but with a cross-sectional design so as to include not only the primary levels but also the secondary and university levels of schooling. This is to see if there is incidence of translanguaging not only in the early years of schooling but also across the whole schooling lifespan. The researchers would like to forward or theorize that the incidence of translanguaging definitely happens in the primary schooling of ESL learners but evidence must be established to support that translanguaging also happens in the secondary and university levels. Hence, further investigation is still needed to establish a stronger grounding of translanguaging as a component in language policy development across the curriculum of basic and higher education.

\section{REFERENCES}

Aliñab, J.M., Aguja, S.E., \& Prudente, M.S. (2018). Improving Pupils’ Mathematics Achievement Through Mother Tongue Based-Multilingual Education. Advanced Science Letters, 24 (7), pp. 4840-4843(4). https://doi.org/10.1166/as1.2018.11213

Baker, C. (2001). Foundations of bilingual education and bilingualism, $3^{\text {rd }}$ edition. Clevedon: Multilingual Matters Ltd.

Bautista, D., Mitchelmore, M., \& Mulligan, J. (2009). Factors influencing Filipino children's solutions to addition and subtraction word problems. Educational Psychology, 29 (6), pp. 729-745. Routledge, Taylor and Francis.

Boonen, A. J. H., Schoot, M., Wesel, F., de Vries, M. H., \& Jolles, J. (2013). What underlies successful word problem solving? A path analysis in sixth grade students. Contemporary Educational Psychology, 38, 271-279. https://doi.org/10.1016/j.cedpsych.2013.05.001

Boonen, A. J., de Koning, B.B., Jolles, J., \& van der Schoot, M. (2016). Word Problem Solving in Contemporary Math Education: A Plea for Reading Comprehension Skills Training. Frontiers in psychology, 7, 191. https://doi.org/10.3389/fpsyg.2016.00191 
Creese, A., \& Blackledge, A. (2010). Translanguaging in the Bilingual Classroom: A Pedagogy for Learning and Teaching? The Modern Language Journal, 94(1), 103-115. Retrieved April 15, 2020, from www.jstor.org/stable/25612290

Cruz, N.T. (2015). The Implementation of the Mother Tongue-Based Multilingual Education in Grade 1 in the Public Elementary Schools in Pangasinan I. Proceedings of the De La Salle University Research Congress, Vol. 3. Retrieved from: https://www.dlsu.edu.ph/wp-content/uploads/pdf/conferences/research-congressproceedings/2015/LLI/014LLI Cruz NT.pdf

Daroczy, G., Wolska, M., Meurers, W. D., \& Nuerk, H. C. (2015). Word problems: a review of linguistic and numerical factors contributing to their difficulty. Frontiers in psychology, 6, 348. https://doi.org/10.3389/fpsyg.2015.00348

Edwards, S., Maloy, R., \& Anderson, G. (2009). Reading Coaching for Math Word Problems. Literacy Coaching Clearinghouse.

Fuchs, L. S., Gilbert, J. K., Fuchs, D., Seethaler, P. M., \& Martin, B. N. (2018). Text Comprehension and Oral Language as Predictors of Word-Problem Solving: Insights into Word-Problem Solving as a Form of Text Comprehension. Scientific studies of reading: the official journal of the Society for the Scientific Study of Reading, 22(2), 152-166. https://doi.org/10.1080/10888438.2017.139825

Garcia, O. (2009). Education, multilingualism and translanguaging in the $21^{\text {st }}$ century. Global and local tensions and promises, pp. 140-158. https://ofeliagarciadotorg.files.wordpress.com/2011/02/education-multilingualismtranslanguaging-21st-century.pdf

Harlaar, N., Kovas, Y., Dale, P. S., Petrill, S. A., \& Plomin, R. (2012). Mathematics is differentially related to reading comprehension and word decoding: Evidence from a genetically-sensitive design. Journal of educational psychology, 104(3), 10.1037/a0027646. https://doi.org/10.1037/a002764

Jitendra, A. K., \& Star, J. R. (2012). An exploratory study contrasting high- and low-achieving students' percent word problem solving. Learning and Individual Differences, 22 (1), 151-158. https://doi.org/10.1016/j.lindif.2011.11.003

Lewis, A. B., \& Mayer, R. E. (1987). Students' miscomprehension of relational statements in arithmetic word problems. Journal of Educational Psychology, 79, 363-371. https://doi.org/10.1037/0022-0663.79.4.363

Owojecho, F.A. (2020). Implementation Challenges of National Language Policy in Nigeria: The Roles of the Indigenous Languages. International Journal of Language and Literary Studies, 2 (1), pp. 270-279. https://doi.org/10.36892/ijlls.v2i1.1833 
Pape, S.J. (2003). Compare word problems: Consistency hypothesis revisited. Contemporary Educational Psychology, Volume 28, Issue 3, pp 396-421. https://doi.org/10.1016/S0361-476X(02)00046-2.

Rasmussen, C. L., \& King, K. D. (2000). Locating starting points in differential equations: a realistic mathematics education approach. International Journal of Mathematical Education in Science and Technology, 31 (2), 161-172. https://doi.org/10.1080/002073900287219

Timmermans, R. E., Van Lieshout, E. C. D. M., Verhoeven, L. (2007). Gender related effects of contemporary math instruction for low performers on problem-solving behavior. Learning and Instruction, 17, pp. 42-54. https://doi.org/10.1016/j.learninstruc.2006.11.005

van der Schoot, M., Bakker Arkema, A. H., Horsley, T. M., \& van Lieshout, E. C. D. M. (2009). The consistency effect depends on markedness in less successful but not successful problem solvers: an eye movement study in primary school children. Contemporary Educational Psychology, 34, pp. 58-66. https://doi.org/10.1016/j.cedpsych.2008.07.002

Vilenius-Tuohimaa, P.M., Aunola, K., \& Nurmi, J.E. (2008). The association between mathematical word problems and reading comprehension. Educational Psychology, 28 (4), 409-426. Routledge, Taylor and Francis.

Whitin, P. \& Whitin, D. J. (2000). Math is language too: Talking and writing in the mathematics classroom. Urbana, IL: National Council of Teachers of English.

Williams, A. B., Metila, R. A., Pradilla, L. A. S., \& Digo, M. M. B. (2014). Teaching Math and Science in the Mother Tongue: Challenges, Strategies, and Perceived Effects.

Assessment, Curriculum and Technology Research Centre, University of the Philippines. Retrieved April 16, 2020 from: https://actrc.files.wordpress.com/2014/11/nismedhandout.pdf

Yonson, D. (2017). Solving word problems performance of students in L1 (Mother Tongue) and L2 (English language). International Journal of Development and Sustainability. Volume 6 Number 8 (2017): pages 628-640.

\section{$\underline{\text { AUTHORS' BIOS }}$}

Judy Cañero Bautista, Ph.D. is an Associate Professor of Reading, Literacy, and Language Education at the College of Graduate Studies and Teacher Education Research of the Philippine Normal University, Manila. His research interests include first and second language acquisition studies, psychology and pedagogy of reading, visual literacy, visual social semiotics, community literacy, language and literacy research methodologies, and verbal protocol analysis. 
Ilynne San Jose Samonte is an Education Program Supervisor of the Department of Education in the Philippines. Her area of focus is English and she is in charge of providing technical assistance in trainings and researches to school heads and teachers. She is a candidate for Ph.D. in Reading Education at the Philippine Normal University.

Cecille Marie Titar Improgo is an Associate Professor at the Bukidnon State University where she has been teaching English for 20 years. Her passion for reading drove her to pursue a Ph.D. in Reading Education at the Philippine Normal University. She is currently working on her dissertation on disciplinary literacy.

Merry Ruth Morauda Gutierrez, Ph.D. is a Full Professor of Reading, Literacy, and Language Education at the College of Graduate Studies and Teacher Education Research of the Philippine Normal University, Manila. Her research interests include first and second language acquisition and learning, comprehension instruction and assessment, and curriculum development in reading and literacy education, among others. 